\title{
REFLECTING ON MATHEMATICS JOURNALS The kaleidoscope effect
}

\begin{abstract}
Alex Neill
K

eeping a journal in the mathematics classroom has clear benefits. Students see that writing a journal is useful to them, teachers gain insights from reading students' responses, and it helps the student-teacher feedback loop. Strong links between journals and self-regulation are made in the research literature, especially as the process of writing helps students think about their own thinking and learning (metacognition).

This article is about a group of students who kept a daily journal on a series of eight mathematics lessons on computational estimation. When they journalled, the students primarily reflected on their mathematical learning. However, when they reflected upon what it was like to keep a journal they become much more regular and deeper metacognitive thinkers. A kaleidoscopic pattern of their reflections on learning appeared.

\section{Metacognition and journalling}

Many writers on self-regulated learning stress the importance of metacognition. Metacognition is often described as thinking about thinking. Zimmerman (1986, cited in Zimmerman 2001, p. 5), says, "students are self-regulated to the degree that they are metacognitively, motivationally, and behaviourally active participants in their own learning process." Lindner (1993), for example, considers metacognition the key to effective self-regulated learning, especially in terms of ensuring transference of learning from familiar to unfamiliar or novel situations (a situation he terms "high-level" transfer). For Darling-Hammond, Austin, Cheung, and Martin (n.d., p. 164), "activities like journalling [are one way of] activating metacognitive skills". This is because, as Bagley and Gallenberger (1992, p. 660) observe, "writing is more than just a means of expressing what we think: it is a means of knowing what we think—a means of shaping, clarifying, and discovering our ideas."
\end{abstract}

\section{Benefits of journalling in mathematics}

The mathematics literature records a range of benefits arising from journalling. Borasi and Rose (1989, p. 348), when discussing journalling in mathematics, note that "educators have suggested powerful connections between writing and learning”. Morgan (2001, pp. 233-234) asserts this as well when she observes that "writing and mathematics are similar activities". She goes on to name other benefits for the student, including the time the writer has to "think about what they are writing and hence to clarify and refine their thinking", and the production of a lasting record. 
Borasi and Rose (1989) describe a range of benefits of journal writing for the student, for the teacher, and for the teacher-student dialogue. For students, the benefits include the therapeutic effect of expressing feelings, increased content knowledge, improved learning and problem solving skills, and gaining a more appropriate view of what mathematics is. For the teacher, there is a gain in knowledge about student learning and the chance to refine both short and long term planning. Student-teacher dialogue leads to more individualised teaching and feedback, as well as creating a more caring, non-adversarial atmosphere.

Zimmerman (1989, 2000a, cited in Zimmerman 2001, p. 5) asserts the importance of this when he says that another feature of most definitions of self-regulated learning is "a self-oriented feedback loop during learning". Journals are an ideal way to provide such feedback. Wilde (1991, p. 42) also comments on this diagnostic potential of journals where the "students' writing will confirm their understanding of a concept." This could either be via their description of a method or be a specific request in their journal for help on something that they don't understand. The teacher who reads the journal can then respond to these immediate requests as well as evaluating their own short- and long-term teaching strategies. Feedback loops are one key element of effective formative assessment. Many of these benefits occurred within the current study.

\section{Methodology}

A series of eight lessons on computational estimation were conducted with a group of nine students from a Year 8 class at a large urban intermediate school. Five were girls, and four were boys. The classroom teacher selected the students and aimed to get a good mix of abilities. For information on the estimation aspects of the research, see Neill (2005).

Before the series of lessons, I conducted a semi-structured interview with each student. This was recorded on video. This included their previous experience of writing journals in mathematics lessons. The students were also encouraged to provide ideas of what might be useful things to include in their journals. These suggestions were incorporated into a list of ideas of what to write about.

Each lesson comprised a teaching and learning time aimed at enriching each student's range of computational estimation strategies. The lessons lasted for about 45-50 minutes and were conducted in a small room that conveniently fitted the nine students. The lessons included whole group teaching, individual work, discussions in groups of three, and whole group discussions. The use of studentto-student dialogue was a central part of the teaching strategy. The groups of students shared each other's ideas and strategies on how they estimated for a range of problems. The groups then shared ideas with the larger group.

At the conclusion of each lesson, students spent 5-10 minutes writing a journal of the day's lesson. During these silent writing times, I modelled the procedure by writing a reflection of the day's lesson on the board as the students wrote in their own journals. After most lessons, students were free to select what they wished to write about. However, after lesson six and at the end of the final lesson the students were asked to spend some of their time writing about the journalling process itself.

At the completion of the series of lessons, I individually interviewed each student again about journalling, including the ways it affected their learning. They were also encouraged to offer suggestions as to how the way they journalled could be changed to make it more effective for them.

\section{Results}

\section{Prior experience of journalling in mathematics}

The pre-study interview showed that none of the nine students had any prior experience in writing a journal specifically focused on their mathematics learning. One said that they had written journals, but in other areas of schoolwork. Many were familiar with the concept, but had never done it in mathematics.

Five students said that they had never been required to write down (even in an ad hoc manner) what or how they learnt in mathematics. One said that they rarely had, and three said that they sometimes had. The students who had at least sometimes written about their mathematics learning mentioned a range of things they recorded. Two of these had written about what they learned. Another said that they had drawn charts and diagrams. One student said that they had written about how they felt about mathematics, and subsequently recorded a range of their feelings in her journal. One commented that they sometimes wrote about mathematics when they started a new topic. Two of the students said that they had talked about these issues more than they had written about them.

\section{Expectations of journalling}

All the students had ideas on what kinds of things they might write about in their journals. Their comments fell into the following six categories:

1. what I did or what I learnt;

2. help that I need or things I need to do or learn more about;

TABLE 1. RESPONSES IN COMMENT CATEGORIES

\begin{tabular}{|lccccc|}
\hline Type of response & $\begin{array}{c}\text { Pre-study interview } \\
\text { expectations }\end{array}$ & Free journalling & $\begin{array}{c}\text { Writing about } \\
\text { journalling }\end{array}$ & $\begin{array}{c}\text { Post-interview } \\
\text { comments }\end{array}$ & Total \\
\hline What I did & $9(31 \%)$ & $83(46 \%)$ & $0(0 \%)$ & $0(0 \%)$ & $92(34 \%)$ \\
Help & $8(28 \%)$ & $21(12 \%)$ & $1(3 \%)$ & $1(3 \%)$ & $31(11 \%)$ \\
Feelings & $4(14 \%)$ & $30(17 \%)$ & $1(3 \%)$ & $3(10 \%)$ & $38(14 \%)$ \\
Easy & $3(10 \%)$ & $10(6 \%)$ & $0(0 \%)$ & $0(0 \%)$ & $13(5 \%)$ \\
Useful & $2(7 \%)$ & $16(9 \%)$ & $18(55 \%)$ & $16(52 \%)$ & $52(19 \%)$ \\
About my learning & $3(10 \%)$ & $18(10 \%)$ & $10(30 \%)$ & $9(29 \%)$ & $40(15 \%)$ \\
Not useful & - & - & $3(10 \%)$ & $2(6 \%)$ & $5(2 \%)$ \\
\hline TOTAL & -29 & -178 & -33 & -31 & -271 \\
\hline
\end{tabular}

Percentages quoted are column percentages (e.g., 9 out of $29=31 \%$ ). 
3. feelings, either what I enjoyed, found good, or didn't enjoy, or how I was feeling;

4. useful or interesting things;

5. easy things or things I already know; and

6. things about my learning (emerging metacognition).

Of these categories, the first two attracted the most comments from the students. These suggestions were incorporated into a list of starter ideas on what students might write about in their journals. This was attached to the front cover of each student's journal.

\section{The journalling experience}

Comments that were made at the pre-study interview, entries made in their journals, and the post-study interview comments were each assigned to one of the six broad categories that emerged from the pre-study interview. The comments in the journals were split by whether they were the result of free journalling or were reflections about the journalling process. A count was kept of the total number of times each category was mentioned. Students often mentioned the same category on several different occasions. A total of 271 separate comments were recorded. The results are in Table 1.

\section{Free journalling}

The student's responses when they were free to choose what to write about were broadly similar to their expectations of journalling in the pre-study interview. The differences between the percentages in the first two columns of Table 1 are not statistically significantly different.

1. What I did or what I learnt. This was by far the most common aspect of student's journals, with 46 percent of comments being on this theme. All students wrote on this and nearly half of the total entries made were of this type. Most often this was a general comment about what had been learned. Describing how different strategies worked was the other main way of recording learning, with seven students doing this voluntarily. Two students did this in most of their journalling times.

2. Help needed was mentioned by seven students and accounted for 12 percent of the comments. This included comments that the work was hard or challenging, or about particular points on which they got stuck. This is excellent feedback to the teacher about specific interventions with particular students. Roughly half these journal entries were notes to themselves about areas of their learning that they needed to give more attention to. These examples of self-initiated goal setting would be excellent catalysts for self-regulated learning as well as for teacher remediation.

3. Feelings. Eight out of the nine students recorded various reactions in their journals, with 17 percent of comments being in this category. For most this was an expression of enjoying the lesson or the context of the lesson. A few found such things as "solid work", "practice", and "finding out about strategies" or "other people's ideas" enjoyable or good. Two expressed gaining extra confidence. One student catalogued a wide range of feelings, both positive and negative, in all but one of the lessons. These ranged from their attitude to themselves, how they felt about mathematics, the topic of the day, or their current frame of mind.

4. Easy things or things I already know. Five students mentioned this, but only 10 comments were recorded on this theme.

5. Useful or interesting things. Four students recorded a total of 16 comments of interesting or helpful aspects of their learning. All but two of these related specifically to estimation strategies, other mathematical ideas, or the context of the lesson. Two commented about interesting ideas they had gained from other students.

6. Things about my learning. Eight students mentioned this, but only in two narrow contexts. Their comments related either to specific things they were getting better at or to ideas and strategies they had picked up from other students or the teacher. Almost all the ideas they attributed to others were gained from other students, with only one being attributed to the teacher. This underlines the power of learning through interaction with peers. Often the person from whom they had got the new idea was named, giving clues to the identities of students who could be key peer tutors.

One girl focused most of her comments on either her feelings or help she needed. The four boys and one of the girls focused at least half their comments on mathematical aspects of what they had learned. The remaining three girls spread their comments more evenly over all six categories.

\section{Reflecting on journalling}

The pattern of the written and oral reflections on journalling were very similar to each other (compare the percentages in columns 3 and 4 of Table 1). The content of these oral and written responses was quite different, however, from the comments made when the students were free to choose what to write about. The two main themes in their reflections on journalling were the usefulness of writing journals and how they thought and learnt as individuals.

1. Useful or interesting things. Over 50 percent of the final interview comments or journal entries were about this. All but one student mentioned the benefits of keeping a journal. Even before the subject of journals was broached in the interview, several students had mentioned that journalling was useful when they were asked what aspects of the series of lessons they found helpful. The key areas in which journalling assisted these students were:

- Remembering. Seven students found it a useful aid to remembering. One said:

When I write it reminds me effortlessly of everything (that) goes through my mind.

- Reflecting. Six students found it useful to look back on their journal. Examples were:

I think it's really good because I can reflect back on what I've learnt and I sometimes read it over again ...

Reflecting on what I thought of things helped me.

- Recording. Four students commented on the positive effect of writing, especially as an aid to learning or remembering, or that they liked the idea of having a record of their learning.

- Organising mathematical thoughts. Some students commented on this. For example:

Writing down the front-end ${ }^{1}$ helped me get used to it more and when to use it.

I think the only thing I have learnt from writing a journal is that by writing something down I can confirm that I know it rather than going away not knowing whether I can do it or can't do [it]. Writing something down eliminates the uncertainty.

Other benefits included finding the teacher comments in the journal useful, getting help with problem areas, and recording details of key things that they learned in the back of the journal.

2. Things about my learning. Reflecting upon journal writing seemed to be the primary place where students started to 
consciously express in writing how they learnt. This accounted for around 30 percent of comments. This was very much "thinking about my learning" rather than just "things about my learning" (as it had been in the free-journalling responses). In other words the students were displaying deeper metacognitive awareness.

- Learning style. Some students identified their learning styles. One recognised that they were a visual rather than an oral learner. Another recognised how writing helped them learn, while a third saw themselves as a person who worked at the "mental level" and saw no need to write.

Writing in a journal helped me learn because I learn by seeing not really hearing. I learn new ideas by seeing and by doing and practising.

I used to just learn, but now I know that writing it down helps me learn.

When I learn stuff I just store it in my head and use it when I need to. I generally don't need any reinforcement.

- Learning conditions. One student mentioned they needed to exert choice to learn effectively.

I didn't really like having no choice...I like to make my own choices.

- Thinking. Several comments were made about how journalling related to thinking.

When you write you think how you learn.

There were experiences that I was not quite sure what I thought of them and when I actually had to think (of what to write). I had to come to a definite answer.

You can write things you can't think and think things you can't write.

Each of these demonstrates awareness of their own thinking or learning. A student who said that they did not see any useful role of journals was thinking about their own thinking when they said:

It's a way to think things over, gather thoughts, and write them down.

The remaining 20 percent or so of the students' comments or journal entries were on the following.

3. Feelings. Four students expressed positive feelings about journal writing. Here are a couple of the things they shared:
I reckon journal writing has helped me because I think it's the way I express my feelings towards maths.

I think it's really good...It inspired me to do more stuff because with it in my book I can.... always look back and feel happy that I've learnt lots of new stuff.

Two students were neutral about it, saying that they didn't mind and did what was asked. The negative feelings expressed were around the issue of writing.

4. Not useful. Three students recorded that journalling had not been particularly useful to them. One said it was because they disliked writing. The others said it was not the way they learnt or that they already knew how they learnt things, which are both metacognitive responses.

5. Help. Two students identified external help that they had obtained as a result of their journal. Another three saw aspects of journalling that would help them to selfregulate. Two of them made comments about how journals were a good way of asking questions. One of the most capable estimators said:

It is good to know what I need to improve on.

\section{Improving journalling}

Some students offered suggestions about how the journalling could be improved. Three people commented that they found it hard to think of things to write about. One of them said this was especially so in the last lessons because they had previously written about all the issues that they could think of. Another said that being given something specific to write on each day would have been helpful. A couple of others thought that the journalling did need something extra but could not think what would help. This indicates that many students require teaching specifically aimed at developing their journal writing skills.

One student suggested that using the back pages of the journal during the lessons to record important mathematical ideas was helpful. This student had made good use of this idea, and others had followed her lead.

\section{Discussion}

\section{Reflecting upon mathematics}

It is interesting to contrast the types of things students focused on when journalling at different parts of the process. Their initial expectations were that it would be primarily a vehicle to write about a wide range of things: what they had learnt (including describing methods they used), feelings about the lesson, things they needed help on, useful things, aspects of how they learnt, what was easy, what they had learnt, and what they needed help on. The pattern of their free-choice journalling was close to the expectations they had expressed in the pre-study interview. Most of these comments focused on mathematical aspects of the lessons.

When student were choosing what to write in their journals, their comments on "thinking about their learning" were relatively naive ones. They were mainly about who they had got new ideas from or whether they thought they were making good progress. Some comments were also made on how they could improve their own learning by being aware of their mathematical weaknesses or where they needed more practice.

From this it can be seen that free-choice reflective journalling is an effective tool in helping students to acquire better mathematical skills and understanding. It helped them record, reflect, organise, and remember their ideas about the mathematics that they had been engaged with. Reflective journalling without free choice was limited in its scope for enhancing these student's understanding and thinking about how they think and learn as individuals.

\section{Reflecting on reflective journalling}

In their journal comments on how they had found journalling or in the post-interview comments, the students focused mainly on two areas: the usefulness (or otherwise) of journals, and their thinking or learning. To become a self-regulated learner a student needs self-awareness of their own learning (that is metacognition). A key to helping these students become self-aware when they wrote journals was to get them to reflect on the journalling process itself. When the nine students did this they came up with a higher proportion of statements about themselves as learners and about thinking on their thinking. The metacognitive statements they made were also of a far more sophisticated nature during this "reflecting on reflective journalling" stage. This included comments on how journalling interacted with and stimulated their thinking, or on their preferred learning styles.

This suggests that either journalling about journal writing or face-to-face discussions about the journalling process help develop and 
make students more aware of the metacognitive dimension so important for them to develop as self-regulated learners.

We may reflect, in conclusion, that reflecting on reflective journalling is a powerful way to enhance metacognition and hence the potential for self-regulated learning in individual students. Perhaps this principle could be called the "kaleidoscope effect". Reflecting in one mirror (the journal) gives but one simple image (see Figures 1 and 2). However, reflecting some reflections using a second mirror gives the multiple images (including images of images and images of mirrors that can themselves in turn be reflected in) which form patterns like those that are seen in a kaleidoscope (see Figure 3). Include a third mirror, or have the two mirrors parallel, and an infinite number of reflected images appear. Journal writing by itself in mathematics can be useful, but mainly focuses on the contexts of the learning. Reflecting on reflective journalling can lead to metacognition and self-regulated learning.

\section{Recommendations}

- Keep a mathematics journal. It helps mathematics learning. It doesn't need to be after every lesson, but should be at least once a week.

- Give active feedback by writing in students' journals or in discussion or conferences with them.

- Scaffold students in writing journals. This is a transactional writing task.

- Use students' comments to initiate goal setting.

- Reflect with your students from time to time on how their journals are going. This could be done orally or in writing. This helps the students think about their thinking and learn about their learning.

\section{References}

Bagley, T., \& Gallenberger, C. (1992). Assessing students' dispositions: Using journals to improve students' performance. The Mathematics Teacher, 85(8), 660-663.

Borasi, R., \& Rose, B. (1989). Journal writing and mathematical instruction. Educational studies in mathematics, 20(4), 347-365.
Alex Neill is a researcher for New Zealand Council for Educational

Research with a specific interests in mathematics education and assessment. He has taught at both primary and secondary levels and worked as an applied mathematician in the DSIR.
Darling-Hammond, L., Austin, K., Cheung, M., \& Martin, D. (n.d.). Session 9: Thinking about thinking: Metacognition. The learning classroom. Retrieved 13 May 2005 from http:www.learner.org/channel/courses/ learningclassroom/support/09_metacog.pdf Lindner, R. (1993, July). Self-regulated learning, metacognition, and the problem of transfer. Paper presented at the $48^{\text {th }}$ International Correctional Association Annual Conference, Chicago. Retrieved 8 June 2005 from http://www.wiu.edu/users/mfrwl/wiu/docs/ ceapre 1 .htm

Morgan, C. (2001). The place of pupil writing in learning, teaching and assessing mathematics. In P. Gates (Ed.), Issues in teaching mathematics (pp. 232-244). London: RoutledgeFalmer.

Neill, A. (2005). Estimation exposed. set: Research Information for Teachers, 1, 48-53.

Wilde, S. (1991). Learning to write about mathematics. Arithmetic Teacher, 38(6), $38-43$.

Zimmerman, B. (2001). Theories of self-regulated learning and academic achievement: An overview and analysis. In B. Zimmerman \& D. Schunk (Eds.), Self-regulated learning and academic achievement theories: Theoretical perspectives (2nd ed., pp. 1-37). New Jersey: Lawrence Erlbaum Associates.

\section{Notes}

1 Front-end (truncation) is a particular computational estimation strategy where only the most significant digit is used.

\section{Email: alex.neill@nzcer.org.nz}

FIGURE 1. LEARNING MIRRORS

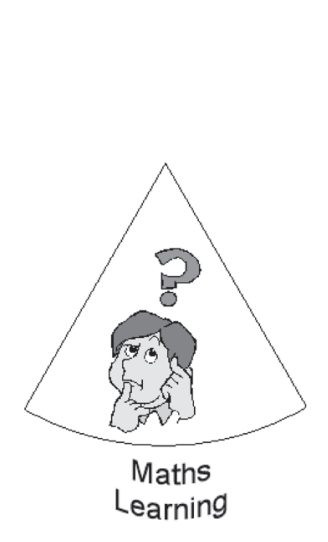

FIGURE 2. REFLECTIVE JOURNALLING MIRROR

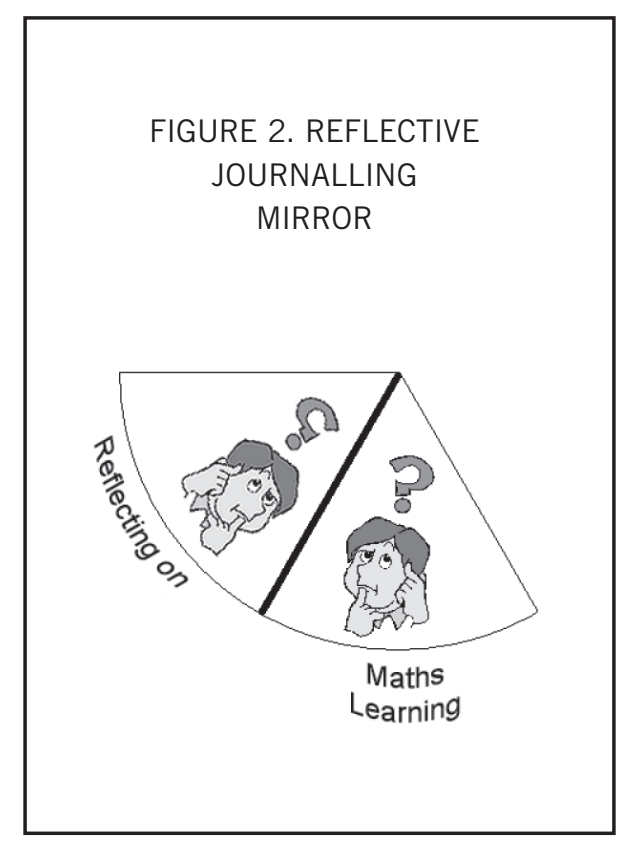

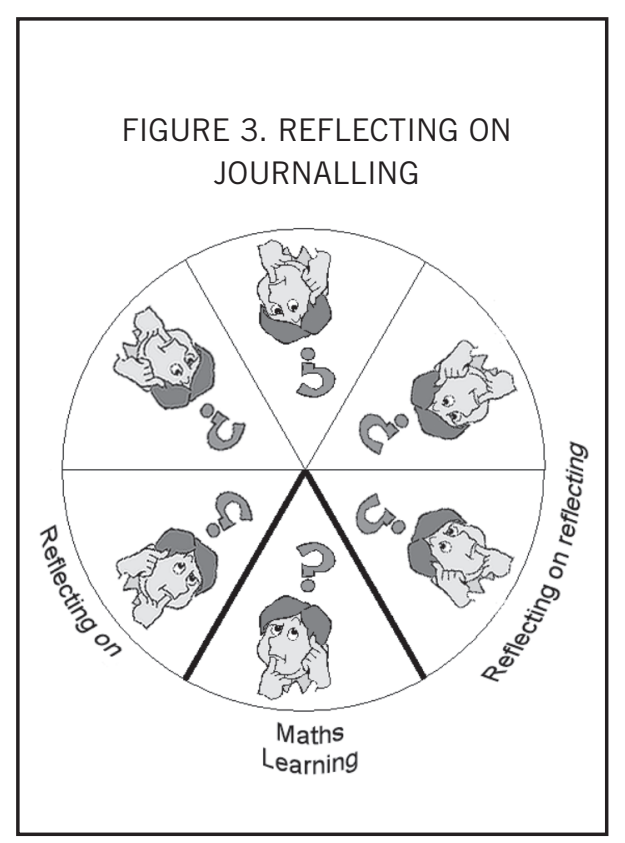

